\title{
CRIANÇA COM DEFICIÊNCIA AUDITIVA E FAMÍLIA: DESAFIOS E CONTRIBUIÇÕES DA PSICOLOGIA
}

\author{
CHILD WITH HEARING DISABILITY AND FAMILY: CHALLENGES AND \\ CONTRIBUTIONS OF PSYCHOLOGY
}

\section{Crislaine Santos Borborema', Fernanda Aguillera'}

Autora para correspondência: Crislaine Santos Borborema - txisiti@gmail.com 'Acadêmica de Psicologia na Faculdade Pio Décimo Décimo. Aracaju, Sergipe, Brasil. http://orcid.org/0000-0003-2611-4906 ${ }^{2}$ Doutora em Psicologia. Docente da Universidade Federal de Sergipe, da Faculdade de Administração e Negócios de Sergipe - FANESE, da Faculdade Estácio de Sergipe - FASE e da Faculdade Pio Décimo. Aracaju, Sergipe, Brasil.

RESUMO | A lei brasileira de inclusão das pessoas com deficiência, sancionada em 2015 , busca assegurar direitos fundamentais a essa parcela da população, visando a sua inclusão social e cidadania. Mas, na prática, essa tarefa está longe de ser consolidada. No caso específico das pessoas com deficiência auditiva e surdez, principalmente se congênitas ou adquiridas na infância, esbarra-se nas dificuldades de comunicação que, além de impactar a família desde - diagnóstico, muitas vezes limitam ou prejudicam o acesso desse público a uma diversidade de serviços, por despreparo dos próprios profissionais. O presente texto objetiva levantar essa discussão, direcionandose aos desafios e contribuições da psicologia junto a criança com deficiência auditiva e seus familiares. Apresenta um breve panorama sobre tal deficiência no Brasil, as possíveis demandas e fazeres do psicólogo diante desses quadros, bem como os recursos adaptativos disponíveis. Ressalta, ainda, os ganhos do devido acompanhamento dos casos, como potencializar o desenvolvimento psicossocial e minimizar prejuízos decorrentes da deficiência, além do devido acolhimento e orientação aos pais, em favor da ressignificação das questões associadas ao problema que possam the trazer sofrimento.

\begin{abstract}
The Brazilian law on the inclusion of people with disabilities, sanctioned in 2015, seeks to guarantee fundamental rights to this part of the population, aiming at their social inclusion and citizenship. But in practice, this task is far from being consolidated. In the specific case of people with hearing loss and deafness, especially if they are congenital or acquired in childhood, they encounter difficulties in communication that, in addition to impacting the family since diagnosis, often limit or hinder the public's access to a diversity of By the professionals themselves. The present text aims to raise this discussion, addressing the challenges and contributions of psychology to the hearing impaired child and their families. It presents a brief overview of such deficiency in Brazil, the possible demands and actions of the psychologist in these frameworks, as well as the adaptive resources available. It also highlights the gains of due follow-up of cases, such as enhancing psychosocial development and minimizing losses due to disability, as well as due care and guidance to parents, in favor of resignifying issues associated with the problem that may bring suffering.
\end{abstract}

Keywords: inclusion; psychology; hearing loss.

Palavras-chaves: inclusão; psicologia; deficiência auditiva. 


\section{INTRODUÇÃO}

A deficiência auditiva na infância pode provocar prejuízos sociais e psíquicos, pois este é o período em que o mundo está sendo apresentado à criança e há a possibilidade de que ela não consiga compreendêlo. Além disso, o seu processo de comunicação poderá ser afetado de forma irreversível. Nesse momento, a interação com $\circ$ meio social possibilita otimizar seu desenvolvimento. Outro fator relevante diz respeito à interação dos pais com as crianças: por pertencerem a um círculo de relações mais próximo, auxiliam experiências importantes na aquisição da linguagem e do desenvolvimento psicossocial.

Dados do Instituto Brasileiro de Geografia e Estatística apontam que, no ano de 2010, aproximadamente 9,7 milhões de brasileiros (cerca de $5,1 \%$ da população) possuíam alguma deficiência auditiva (DA). Deste total, cerca de 2 milhões possuem a deficiência auditiva severa $(1,7$ milhões têm grande dificuldade para ouvir e 344,2 mil são surdos), enquanto 7,5 milhões apresentam alguma dificuldade auditiva (ADAP, 2013). No que se refere à idade, cerca de um milhão de pessoas com deficiência auditiva são crianças e jovens até os 19 anos.

De acordo com Isaac e Manfredi (2005), a audição é um sentido importante na comunicação humana, pois é através dela que o homem adquire a linguagem, além da mesma contribuir com desenvolvimento educacional, emocional e social. Privados desse sentido, o surdo ou o deficiente auditivo têm sua inserção na sociedade dificultada, pois não raro são ignorados ou desprezados pelas outras pessoas, além de não conseguirem alcançar suas metas. Frente a esse fato, a Libras - Língua Brasileira de Sinais - surgiu como uma alternativa de o surdo ser reinserido na sociedade e se comunicar com outros surdos (Monteiro, 2006).

Nesse contexto, a orientação de um psicólogo ganha considerável importância. Propostas de trabalho direcionadas à deficiência auditiva preocupamse, basicamente, com as abordagens educacionais para os surdos em defesa da cultura surda. Frente $a$ isso, pode-se afirmar que é recente 0 interesse da Psicologia pelo tema, de forma mais sistemática, a partir das políticas públicas de inclusão. Até pouco tempo a deficiência auditiva era objeto de estudo somente de médicos e educadores; e, mais recentemente, ganhou a atenção de fonoaudiólogos e psicólogos. Mas, como pode atuar o psicólogo diante dos desafios da comunicação que essa realidade pressupõe?

Falta de comunicação, preconceitos e isolamento fazem com que as pessoas com deficiência auditiva, ainda que tenham conseguido avançar em seu desenvolvimento e relações interpessoais, sejam "dependentes" do ouvinte. Frente a isso, discutese que uma das grandes dificuldades das mesmas se refere a lidar com suas emoções e sentimentos. Desse modo, o atendimento psicológico junto a tal público requer uma gama de condições que exigem do terapeuta dedicação e paciência de modo diferenciado, bem como uma postura profissional aberta, calcada numa visão holística do atendimento, considerando-se as dimensões física/ sensorial e mental do cliente. (Gonçalves, 2014).

Além disso, especialmente na infância, o atendimento aos deficientes auditivos deve considerar a necessidade de um trabalho interdisciplinar: fonoaudiólogo, psicopedagogo, professores, psicólogo e profissionais de outras especialidades podem contribuir em favor do desenvolvimento integral dessa clientela. $E$ as ações que envolvem a família são essenciais no processo, desde que resguardada a ética profissional.

$\grave{A}$ vista do exposto, o presente artigo propõe-se a discutir o que é ser deficiente auditivo no país e como pode, nesse contexto, atuar o psicólogo, tendo em vista demandas específicas do público em questão.

\section{A deficiência segundo as leis brasileiras}

Segundo Teixeira (2010), são consideradas pessoas portadoras de deficiência (PPD) os cidadãos que apresentam, em caráter permanente, perdas ou reduções em sua estrutura ou função anatômica, fisiológica, psicológica ou mental, que gerem limitação ou incapacidade para exercer atividades 
consideradas "normais" para os seres humanos.

No que diz respeito à deficiência auditiva, estão incluídas as perdas de audição leves, severas, moderadas e profundas, além da surdez total. As perdas podem ser classificadas, segundo o Ministério da Educação (2006), como:

a) Perda moderada - incapacidade em ouvir sons menores que 50 decibéis, podendo ser tratada com aparelhos e acompanhamento;

b) Perda severa - não se ouve sons abaixo de 80 decibéis;

c) Perda profunda - não se escuta nenhum som que seja emitido abaixo de 91 decibéis. Nesses casos, os aparelhos e as órteses auxiliam parcialmente; porém, recomenda-se o aprendizado em Libras.

Quanto ao grau das deficiências auditivas e seus reflexos no desenvolvimento, Furlaneto, Buffa e Silva (2010) defendem que, quando são classificadas como leves, caso não progridam, o problema não traz efeitos significativos no desenvolvimento da pessoa. Isso começa a ocorrer se a deficiência for moderada, pois afeta e atrasa o desenvolvimento da linguagem e da fala. No entanto, não impede que o sujeito fale, a partir de uma intervenção terapêutica, e, com o uso do Aparelho de Amplificação Sonora Individual (AASI), o desenvolvimento poderá se tornar normal.

A deficiência auditiva severa, por sua vez, pode interferir no desenvolvimento da fala e linguagem. Entretanto, com o uso de AASI, suporte da família e ajuda de profissionais especializados, o sujeito poderá desenvolver a fala e o aprendizado da linguagem. Mas em casos de deficiência profunda, a linguagem e a fala dificilmente se desenvolvem sem uso de aparelhos auditivos.

No dia 6 de julho de 2015, foi instituída a Lei No 13.146: a Lei Brasileira de Inclusão da Pessoa com Deficiência, também conhecida como Estatuto da Pessoa com Deficiência. Busca promover e assegurar o exercício dos direitos e das liberdades fundamentais para as pessoas com deficiência, visando a sua inclusão social e cidadania. Para efeito da lei, considera-se pessoa com deficiência como sendo aquela que apresenta impedimento de longo prazo de natureza física, mental, intelectual ou sensorial, o qual, em interação com uma ou mais barreiras, pode obstruir sua participação plena e efetiva na sociedade em igualdade de condições com as demais pessoas. (Brasil, 2015).

Ainda segundo essa lei, a avaliação da deficiência deve ser biopsicossocial, realizada por equipe multiprofissional e interdisciplinar. Para isso, considerar-se-á: os impedimentos nas funções e nas estruturas do corpo; os fatores socioambientais, psicológicos e pessoais; a limitação no desempenho de atividades; e a restrição de participação.

A lei ainda dispõe de esclarecimentos acerca de conceitos e termos utilizados no contexto do trabalho com as diversas deficiências. Alguns deles são: 1) Comunicação: forma de interação dos cidadãos que abrange as línguas, inclusive a Língua Brasileira de Sinais (Libras), a visualização de textos, o Braille, o sistema de sinalização ou de comunicação tátil, os caracteres ampliados, os dispositivos multimídia, assim como a linguagem simples, escrita e oral, os sistemas auditivos e os meios de voz digitalizados e os modos, meios e formatos aumentativos e alternativos de comunicação, incluindo as tecnologias da informação e das comunicações; 2) Atendente pessoal: pessoa, membro ou não da família, que, com ou sem remuneração, assiste ou presta cuidados básicos e essenciais à pessoa com deficiência no exercício de suas atividades diárias, excluídas as técnicas ou os procedimentos identificados com profissões legalmente estabelecidas; 3) Profissional de apoio escolar: pessoa que exerce atividades de alimentação, higiene e locomoção do estudante com deficiência e atua em todas as atividades escolares nas quais se fizer necessária, em todos os níveis e modalidades de ensino, em instituições públicas e privadas, excluídas as técnicas ou os procedimentos identificados com profissões legalmente estabelecidas; 4) Acompanhante: aquele que acompanha a pessoa com deficiência, podendo ou não desempenhar as funções de atendente pessoal. A previsão desse conjunto de agentes e providências destina-se a assegurar que a pessoa com deficiência tenha acesso a igualdade de direitos, bem como toda liberdade para que seja feita sua inclusão social. No caso específico da pessoa com deficiência auditiva, considera-se que, na aplicação da lei, a comunicação deve ser a forma de interação entre os cidadãos, devendo abranger a Língua Brasileira 
de Sinais (LIBRAS), a comunicação tátil nos casos de surdo-cegueira, assim como toda forma de comunicação alternativa e aumentativa.

\section{Demandas e atuação do psicólogo junto à pessoa com deficiência auditiva e família}

Quando uma criança, filha de pais ouvintes, é diagnosticada com perda auditiva, as emoções se misturam tanto para seus familiares, quanto para a própria criança, envolta às reações de todos a seu redor. Tendo em vista as fortes emoções, inseguranças e receios provocados pela descoberta, mostra-se imprescindível que a família receba $\circ$ apoio de um profissional de psicologia. $O$ psicólogo pode atuar, nesse contexto, orientando o deficiente e sua família para que o sofrimento deles seja minimizado, a partir de uma possível ressignificação das questões que trazem mal-estar aos envolvidos, principalmente o surdo.

Em décadas passadas, existiam famílias ouvintes que "escondiam" os filhos surdos por acreditarem ser uma vergonha para a família. A comunicação com eles era feita por gestos ou mímicas e, consequentemente, havia uma rejeição à língua de sinais, como forma de negação da deficiência. De acordo com Monteiro (2006), por muitos anos, devido a esta cultura de rejeição, preconceito e marginalização a que estavam sendo submetidos, os próprios surdos não compreenderam a importância da comunicação através da Língua de Sinais, assim como da construção da Identidade e Cultura Surda Brasileira.

A comunicação tem função primordial na relação entre indivíduos. Na vida de uma criança deficiente auditiva, se faz fundamental na interação da criança com o meio social e ao seu desenvolvimento integral. O comportamento de uma criança se baseia no contexto em que ela vive, como dizem Domingues, Motti e Palamin (2008). Sendo assim a deficiência auditiva acarreta implicações na vida das crianças diagnosticadas com tal deficiência.

Ao receberem o diagnóstico de deficiência auditiva de seu filho, os pais sentem-se impotentes, pois não raro julgam-se incapazes de educar a criança, consideradas suas necessidades especiais. Segundo
Aiello (2013), observa-se ainda que o luto ocorre concomitantemente à raiva, pois, para estes pais, trata-se da violação da expectativa de terem um filho "perfeito". O descontrole também se faz presente na vida dos mesmos, especialmente relacionado à sua capacidade de lidar com a situação. Daí a importância de um acompanhamento psicológico do caso, tanto para efeito de elaboração das emoções e conflitos, como para orientação sobre o problema e formas de lidar com ele, de modo a minimizar seus impactos.

Com o ambiente familiar já adaptado à criança com deficiência auditiva, tão logo ela cresce e tem que conviver com uma comunidade ouvinte, que muitas vezes é receosa com o diferente. Para que essa nova etapa de adaptação ao meio social ocorra da maneira mais tranquila possível, - apoio do psicólogo é fundamental para auxiliar no empoderamento do deficiente, de forma que ele entenda que merece um lugar digno, funcional e respeitável na sociedade. Frente a isso, destaca-se a importância das habilidades sociais, favoráveis à sua inserção no meio social.

Na infância, a promoção de tais habilidades tende a resultar num desenvolvimento emocional satisfatório das crianças e na garantia de seu bem-estar social. Em especial no caso das crianças diagnosticadas com deficiência auditiva, investir na promoção de tais habilidades parece ser um caminho promissor. Autocontrole, expressividade emocional, civilidade, empatia, assertividade, solução de problemas e a habilidade de fazer amizades também devem se fazer presentes na vida delas. Del Prette e Del Prette (2006) ainda destacam a importância das habilidades sociais educativas de pais e educadores, em geral, na promoção da comunicação e do repertório social da criança.

Em favor do desenvolvimento da criança com deficiência auditiva em seu meio social e familiar, atenção especial deve ser dada ao aprimoramento da comunicação, quando a mesma se mostra comprometida. Nesses casos, o uso da Comunicação Alternativa e Ampliada (CAA) pode ser um caminho, que tem se mostrado eficaz na prática clínica junto a crianças e seus familiares. Como ressalta Nunes (2003, citado por Paula e Enumo, 2007), a comunicação alternativa visa compensar prejuízos 
na linguagem (oral e escrita) e desordens na comunicação expressiva. Faz-se uso de diferentes meios de comunicação que são derivados de gestos, expressões faciais, símbolos, figuras, linguagem de sinais, entre outros, que podem ser empregados de forma substantiva e de apoio à fala, ajudando a desenvolver, sempre que possível, a linguagem oral. Como se pode perceber, são muitas os desafios, mas também os meios e recursos que possibilitam interações positivas e a promoção do desenvolvimento junto a crianças com deficiência auditiva e seus familiares. Demanda de suma importância ao trabalho do psicólogo, cabe a esse profissional reconhece-la, abrir-se a tal possibilidade e apropriar-se dos instrumentais necessários a uma atuação coerente e cabível a essa realidade.

\section{CONSIDERAÇÕES FINAIS}

Ainda há muito a ser feito para que a pessoa com deficiência seja incluída de forma integral na sociedade, para que seja aceita como igual em suas diferenças, para que tenha as mesmas oportunidades e tratamentos dos outros cidadãos. E garantir - acesso ao atendimento psicológico ou demais serviços de psicologia é um passo importante nesse sentido, quando se trata da pessoa com deficiência auditiva ou que vivencia a surdez. As dificuldades e/ou limites de comunicação, até bem pouco tempo vistos por muitos como restritivos ao atendimento psicológico, hoje já se reconhecem superáveis desde a infância, adotando-se os recursos, meios e adaptações necessárias.

A família tem papel fundamental para que, a partir da aceitação do diagnóstico, busque auxílio e tratamento em favor do desenvolvimento integral da criança. Vê-se que a Lei da Inclusão está consolidada e visa assegurar liberdade em sua inclusão social. Porém, sabe-se que esta inclusão ainda está bastante aquém daquilo que a mesma propõe, no caso dos deficientes auditivos, pois nem sempre a comunicação e interação entre os ouvintes e os não-ouvintes é feita de forma correta, uma vez que faltam muitos recursos, informação e a sensibilização de todos para lidar com a situação de uma forma mais positiva.

A atuação do psicólogo frente a tal realidade, desde o diagnóstico e durante o tratamento é de suma importância, pois além de auxiliar a família no processo de luto por um filho idealizado e aceitação do filho real, ajuda a promover uma adaptação mais saudável e tranquila dessa criança com deficiência aos contextos em que será inserida, da escola ao trabalho no futuro. É fato que ela terá que enfrentar inúmeros obstáculos, desde os momentos iniciais de diagnóstico, os percalços da reação familiar ao mesmo, até sua inserção educacional e social mais ampla. Instrumentalizá-la para lidar com os desafios da convivência e garantir suporte emocional frente aos mesmos é tarefa não apenas do psicólogo, mas também da família, que deve estar devidamente orientada para isso.

Por fim, espera-se que as informações e reflexões presentes nesse texto contribuam para despertar o interesse de profissionais da psicologia, mais especificamente, mas também da saúde em geral, por se abrirem para outras formas de comunicação, que atendam às necessidades das pessoas com deficiência auditiva e/ou surdez. Fica o convite para se disporem a esse desafio, se prepararem e contribuírem para a ampliação do acesso aos serviços de saúde a essa parcela significativa da população, participando ativamente da construção de uma sociedade inclusiva e mais justa.

\section{CONTRIBUIÇÕES DAS AUTORAS}

\footnotetext{
Borborema CS foi a responsável pelo levantamento bibliográfico que norteou o artigo de revisão em questão, além de proceder as leituras, realizar os fichamentos e a seleção dos aspectos a contemplar na construção do texto. Aguillera $F$ foi responsável pela orientação do trabalho, desde o refinamento do tema até a revisão final do texto, o que contempla: o ensino dos procedimentos e fontes de busca bibliográfica, além de noções básicas de escrita científica, a orientação das leituras dirigidas, a discussão das ideias gerais para direcionamento aos objetivos e dos resultados encontrados, acompanhamento semanal e correção da construção gradativa do texto até sua conclusão e submissão à revista. Vale esclarecer ainda que a definição dos objetivos foi tarefa conjunta, apoiada nos interesses de pesquisa da primeira autora e frente à lacuna no conhecimento identificada: reduzida produção científica acerca da prática do psicólogo junto a pacientes com deficiência auditiva e surdos.
} 


\section{CONFLITOS DE INTERESSES}

Nenhum conflito financeiro, legal ou político envolvendo terceiros (governo, empresas e fundações privadas, etc.) foi declarado para nenhum aspecto do trabalho submetido (incluindo mas não limitandose a subvenções e financiamentos, conselho consultivo, desenho de estudo, preparação de manuscrito, análise estatística, etc).

\section{REFERÊNCIAS}

Aiello, C. P., \& Ferrari, D. V. (2015). Telessaúde em Audiologia: avaliação da eficácia de uma rede social on-line como apoio aos pais de crianças candidatas ao implante coclear. In CoDAS, 27(5), $411-418$.

Associação de Deficientes Auditivos Pais, Amigos e Usuários de Implante Coclear. (2013). Portal ADAP. Recuperado de http://www.adap.org.br/site/index.php.

Domingues, A. F., Motti, T. F. G. \& Palamin, M. E. G. (2008). O brincar e as habilidades sociais na interação da criança com deficiência auditiva e mãe ouvinte. Estud. psicol, 25(1), 37-44. doi: 10.1590/S0103$\underline{166 \times 2008000100004}$

Furlaneto, M., Buffa, M. J. M. B., \& da Silva, C. (2010). Percepção e participação da família no contexto escolar de crianças com implante coclear. Serviço Social \& Realidade, 19(2), 171-202.

Gonçalves, P. C. S. (2014). Atendimento psicológico para surdos. Portal Editora Arara Azul, 9(4).

Isaac, M. L, \& Manfredi, A. K. S. (2005). Diagnóstico precoce da surdez na infância. Medicina, Ribeirão Preto, 38(3/4), 235-244.

Lei n. 13.146, de 6 de julho de 2015. (2015). Institui a Lei Brasileira de Inclusão da Pessoa com Deficiência (Estatudo da Pessoa com Deficiência. Brasília. Recuperado de http://www.planalto.gov.br/ccivil_03/_ato20152018/2015/Lei/L13146.htm.

Brasil, Ministério da Educação. (2006). Saberes e práticas da inclusão: desenvolvendo competências para o atendimento às necessidades educacionais especiais de alunos surdos. Brasília: MEC, Secretaria de Educação Especial, 2006. 116 p. Recuperado de http://portal.mec.gov.br/seesp/ arquivos/pdf/alunossurdos.pdf

Monteiro, M. S. (2006). História dos surdos e o reconhecimento da Libras no Brasil. Educação Temática Digital, 7(2), 292-302. Recuperado de https://dialnet.unirioja.es/ descarga/articulo/4856350.pdf.

Paula, K.M.P. de , \& Enumo, S.R.F. (2007). Avaliação assistidia e comunicação alternativa: procedimentos para a educação inclusiva. Revista Brasileira de
Educação Especial, 13(1)3-26. doi: 10.1590/S1413$\underline{65382007000100002}$

Teixeira, M. C. A. (2010). Políticas Públicas para pessoas com deficiência no Brasil. (Dissertação mestrado) - Escola de Administração de Empresas de São Paulo, Fundação Getúlio Vargas. São Paulo. 